\title{
Usulan Pengurangan Jumlah Cacat Part Produk Frame X
}

\author{
Muhammad Musafak ${ }^{1}$, Johan K. Runtuk ${ }^{2,}$ Sumartono ${ }^{3}$ \\ ${ }^{1,2}$ Faculty of Engineering, Industrial Engineering Department, President University \\ Jl. Ki Hajar Dewantara \\ Kota Jababeka,Cikarang, Bekasi - Indonesia 17550 \\ Email: ${ }^{1}$ safak9092@gmail.com, ${ }^{2}$ johan.runtuk@president.ac.id, ${ }^{3}$ sumartono@cikarangdryport.com
}

\begin{abstract}
ABSTRAK
Kualitas memegang peranan penting dalam perusahaan. Jika kualitas produk tidak sesuai dengan harapan pelanggan, maka akan menimbulkan keluhan pelanggan dan bahkan berakibat pada ketidakpercayaan pelanggan terhadap perusahan. PT. XYZ mengalami peningkatan keluhan pelanggan pada bulan November 2017, yaitu sebanyak 13.178 pcs. Part cacat yang terbesar adalah frame $x$ dan masalah visual. Setelah melakukan analisis diagram tulang ikan, diketahui bahwa penyebab tingginya keluhan pelanggan dan problem internal frame X di PT XYZ disebabkan oleh faktor metode dan material. Berdasarkan hasil analisis lebih lanjut, maka dirumuskan rencana perbaikan meliputi: pembuatan check sheet, flow chart, dan menuntut perbaikan ke suplier collar agar terus membuat produk sesuai standar. Setelah melakukan perbaikan, diketahui bahwa pada bulan Desember 2017, jumlah cacat menurun sebesar $54.27 \%$.
\end{abstract}

Keywords: kualitas, frame $x$, diagram tulang ikan, perbaikan

\section{ABSTRACT}

Quality has an important role in a company. A defect product can The customer complaint of PT XYZ keep increasing in November 2017 in amount of 13.178 pcs. The highest defect occurred on frame $X$ and visual problem. After analyzing using fishbone diagram, the cause of highest defect is caused by method and material.

\section{Pendahuluan}

Pengendalian kualitas adalah suatu sistem verifikasi dan penjagaan dari suatu tingkatan kualitas produk atau proses yang dikehendaki dengan cara perencanaan yang seksama, pemakaian peralatan yang sesuai, inspeksi yang terus menerus, serta tindakan korektif bilamana diperlukan. Dengan demikian hasil yang diperoleh dari kegiatan pengendalian kualitas benar-benar dapat meningkatkan kualitas dari suatu produk serta memenuhi standar-standar yang telah ditetapkan oleh pelanggan. Bila aktivitas ini tidak dilakukan dengan baik, maka akan menimbulkan banyaknya produk cacat di perusahaan.

PT XYZ mengalami peningkatan keluhan pelanggan terkait adanya part cacat yang terkirim ke pelanggan. Part cacat yang dihasilkan perusahaan cukup banyak, sebagai contoh pada bulan November 2017 sebanyak 13.178 pcs part yang dikeluhkan oleh pelanggan. Hal ini berakibat pada kekecewaan pelanggan, dan bila tidak segera ditangani akan membuat perusahaan kehilangan pelanggan pelanggan dan mengalami kerugian.

Setelah dilakukan kajian terhadap data keluhan pelanggan, didapatkan bahwa part yang sering cacat adalah frame. Keluhan yang utama adalah akibat dari pengelasan yang tidak standar. Oleh karena itu, diperlukan adanya suatu upaya untuk mereduksi part cacat ini agar dapat meingkatkan kembali kepercayaan pelanggan terhadap perusahaan. Hal ini juga akan berdampak kepada peningkatan keuntungan bagi perusahaan.

Pada penelitian ini, pertama kali akan dilakukan identifikasi terhadap akar penyebab terjadinya masalah part cacat. Selanjutnya akan dilakukan tindakan perbaikan untuk mereduksi cacat part tersebut. 


\section{Kajian Pustaka}

\subsection{Proses Produksi}

Menurut Assauri (2008) mengungkapkan bahwa proses produksi dapat dibedakan atas dua jenis, yaitu:

1. Proses produksi yang terus-menerus (continuous processes) Proses produksi yang terus-menerus adalah proses produksi yang dipersiapkan untuk memproduksi produk dalam jangka waktu yang lama/panjang, tanpa mengalami perubahan untuk jenis produk yang sama.

2. Proses produksi yang terputus-putus (intermittent processes) Proses produksi yang terputus-putus adalah proses produksi yang menggunakan waktu yang pendek dalam persiapan peralatan untuk perubahan yang cepat guna dapat menghadapi variasi produk yang berganti-ganti.

3. Proses Intermediate

Dalam kenyataan kedua macam proses produksi diatas tidak sepenuhnya berlaku. Biasanya merupakan campuran dari keduanya. Hal ini disebabkan macam barang yang dikerjakan memang berbeda,tetapi macamnya tidak terlalu banyak dan jumlah barang setiap macam agak banyak. Proses produksi uang memiliki unsur continuous dan ada pula unsur intermittennya, proses semacam ini biasanya disebut sebagai proses intermediate atau campuran.

\subsection{Pemeriksaan}

Definisi pemeriksaan menurut Mulyadi (2002) adalah suatu proses sistematik untuk memperoleh dan mengevaluasi bukti secara objektif mengenai pernyataan tentang kejadian ekonomi, dengan tujuan untuk menetapkan tingkat kesesuain antara pernyataan tersebut dengan kriteria yang telah ditetapkan, serta penyampaian hasil-hasilnya kepada pemakai yang berkepentingan.

Pemeriksaan dilakukan dalam rangka pengendalian suatu kegiatan yang dijalankan oleh suatu unit usaha tertentu. Oleh karena itu, pemeriksaan merupakan bagian dari pengawasan sedangkan pengawasan merupakan bagian dari pengendalian. Pengawasan terdiri dari pengawasan dan tindak lanjut. Suatu pengawasan akan menghasilkan temuan-temuan yang memerlukan tindak lanjut. Apabila keseluruhan tindak lanjut itu dilakksanakan, maka keseluruhan pekerjaan tersebut merupakkan pengendalian. Akan tetapi bilamana tindak lanjut tidak dilaksanakan maka tetap dinamakan pengawasan.

\subsection{Keluhan Pelanggan}

Keluhan pelanggan merupakan ungkapan dari ketidakpuasan yang dirasakan oleh konsumen. Keluhan pelanggan adalah hal yang tidak dapat dianggap remeh karena dengan mengabaikan hal tersebut akan membuat konsumen merasa tidak diperhatikan dan pada akhirnya perusahaan akan ditinggalkan oleh konsumen. Keluhan pelanggan membutuhkan penanggulangan segera agar perusahaan dapat mengatasi dengan cepat apa yang menjadi penyebab ketidaksukaan pelanggan. Diharapkan pada akhirnya dimasa selanjutnya tidak ada lagi pelanggan yang mengeluhkan hal serupa pada perusahaan.

Menurut Rangkuti (2003) keluhan dibagi menjadi dua macam yaitu:

a. Keluhan yang telah disampaikan secara lisan, melalui telepon atau komunikasi secara langsung.

b. Keluhan yang dilakukan secara tertulis melalui guest complaint form.

Keluhan pelanggan menurut Engel (Rangkuti, 2003) dapat disampaikan secara langsung ataupun melalui media tertentu. Secara langsung misalnya dengan mengungkapkan secara lisan kepada perusahaan. Keluhan pelanggan dapat juga disampaikan melalui media tertentu misalnya dengan menulis surat yang dimasukkan dalam kotak surat yang dimasukkan ke dalam kotak surat perusahaan atau menulis pada media massa seperti koran dibagian kolom pembaca. Perusahaan lebih mudah memberikan feedback pada pelanggan yang menyampaikannya secara langsung dan akan sulit memberikan feedback pada pelanggan yang menyampaikannya secara tidak langsung. Maksudnya, perusahaan tentu saja akan dapat jelas mengetahui apa yang menjadi permasalahan pelanggan jika pelanggan menyampaikannya secara langsung. Perusahaan dapat secara detail menanyakan apa yang menjadi ketidaknyamanan pelanggan yang dikeluhkan pelanggan.

\subsection{Tujuh Alat Bantu Kualitas}

Pimpinan organisasi membutuhkan alat yang dapat membantu dalam melihat aktivitas perbaikan yang telah dilakukan dan dalam mengambil keputusan. Alat bantu kualitas dapat digunakan dalam semua tahapan proses produksi mulai dari awal pengembangan produk hingga menjadi sebuah produk dan dukungan pelanggan. Tujuh alat bantu kualitas telah berhasil 
diaplikasikan pada beberapa perusahaan dan proses produksi dengan baik. Tujuh alat bantu kualitas itu adalah:

1. Flow chart.

Flow chart adalah sebuah diagram alir yang biasa digunakan untuk prosedur operasional dalam menyederhanakan sebuah sistem. Flow chart dapat mengidentifikasi sebuah bottleneck dari sebuah proses, proses-proses yang berlebih dan proses yang tidak memberi nilai tambah.

2. Diagram sebab akibat.

Diagram sebab akibat diperkenalkan pertama kali oleh Kouru Ishikawa pada tahun 1943. Diagram ini berguna untuk menganalisis dan menemukan faktor-faktor yang berpengaruh secara signifikan didalam menemukan karakteristik kualitas output kerja. Disamping itu juga untuk mencari penyebab-penyebab yang sesungguhnya dari suatu masalah.

3. Check sheet.

Check sheet merupakan alat bantu untuk memudahkan proses pengumpulan data. Bentuk dan isinya disesuaikan dengan kebutuhan maupun kondisi kerja yang ada. Didalam pengumpulan data maka data yang diambil harus benar-benar sesuai dengan kebutuhan analisis.

4. Diagram pareto.

Diagram pareto diperkenalkan pertama kali oleh seorang ahli ekonomi dari Italia yang bernama Vilfredo Pareto. Diagram pareto dibuat untuk menemukan masalah atau penyebab yang merupakan kunci dalam penyelesaian masalah dan perbandingan terhadap keseluruhan.

5. Histogram.

Histogram adalah salah satu alat dari metode statistik yang digunakan untuk menganalisis data. Untuk menganalisis sebuah histogram lebih lanjut, terutama apabila terjadi penyimpangan, maka data tersebut harus dikelompokkan untuk satu jenis pengamatan yang sama sebab distribusi data yang satu mungkin akan berbeda dengan distribusi data lainnya. Dengan pengelompokan data ini, maka analisis akan lebih mudah dibuat.

6. Scatter diagram.

Scatter diagram digunakan untuk melihat korelasi dari suatu faktor penyebab yang berhubungan terhadap faktor lain. Dari penyebaran titik-titik (scatter) bias dianalisis hubungan sebab akibat yang ada.

7. Control chart.

Control chart adalah suatu grafis perbandingan dari hasil sebuah proses dengan estimasi batas kontrol yang dimasukkan ke dalam bagan. Biasanya proses hasil terdiri dari kelompok pengukuran yang dikumpulkan secara teratur dan yang sama.

Tujuan utama dari control chart adalah untuk menemukan penyebab spesifik dari hasil produksi. Batas kontrol dikenal dengan batas kontrol atas dan batas kontrol bawah. Dengan control chart ini dapat menganalisis dan mengevaluasi kondisi-kondisi yang dianggap tidak normal.

\section{Metodologi Penelitian}

Pada penelitian ini akan dilakukan beberapa tahapan penelitian. Tahapan pertama adalah melakukan observasi awal untuk menemukan permasalahan yang dihadapi perusahaan. Tahap kedua adalah identifikasi masalah. Tujuan tahap kedua adalah menentukan tujuan dan batasan dari penelitian. Tahapan ketiga adalah studi literatur yang akan digunakan sebagai dasar teori dalam menyelesaikan masalah. Tahap keempat adalah melakukan pengumpulan dan analisis data. Tahap kelima adalah membuat kesimpulan dan saran dari penelitian. Tahapan-tahapan penelitian tersebut dirangkum pada Gambar 1.

\section{Hasil dan Pembahasan}

Terdapat beberapa part cacat yang dialami oleh perusahaan. Untuk mengetahui part cacat terbesar di yang terjadi di departemen pengelasan, maka dikumpulkan data keluhan pelanggan di bulan November dan ditampilkan melalui diagram pareto yang dapat dilihat pada Gambar 2.

Dari Gambar 2 dapat diketahui bahwa produk frame $X$ di peringkat pertama keluhan pelanggan dengan jumlah keluhan pelanggan 958 unit atau 11.47\%, selanjutnya keluhan pelanggan yang diterima oleh frame $X$ di petakan menjadi 2 yaitu keluhan pelanggan dari masalah visual dan dimensi. Berdasarkan pengamatan lebih lanjut terhadap keluhan pelanggan, diketahui bahwa keluhan masalah visual lebih banyak daripada keluahan masalah dimensi, yaitu sebesar $65.65 \%$. Oleh karena itu, perusahaan menentukan target untuk menurunkan tingkat cacat $10 \%$ pada proses pengelasan dengan fokus perbaikan visual part. 


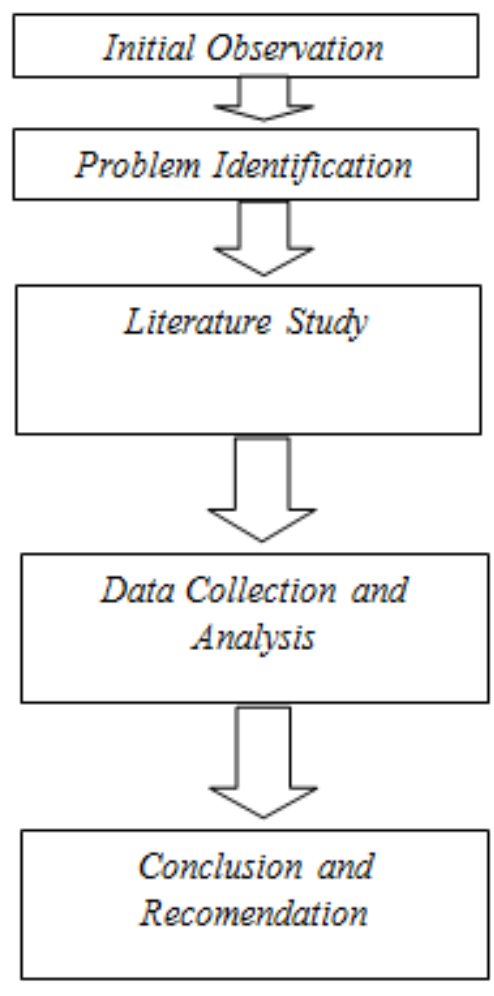

\section{Initial Observation \\ Identifikasi masalah yang terjadi di lini A}

\section{Problem Identification}

Identifikasi latar belakang masalah

- Menentukan tujuan dari penelitian

- Menentukan batasan dari penelitian

Literature Study

Materi pembelajaran mengenai proses produksi, pengelasan,

PDCA dan Pemeriksaan.

Data Collection dan Analysis

1. Data masalah yang ada di lini A

2. Grafik pareto masalah lini A

3. Analisis masalah

Conclusion dan Recomendation

- Kesimpulan dan rekomendasi dari hasil penelitian

- Saran yang dapat diterapkan dan dikembangkan lebih jauh untuk penanganan masalah dimasa depan

Gambar 1 Flowchart Penelitian

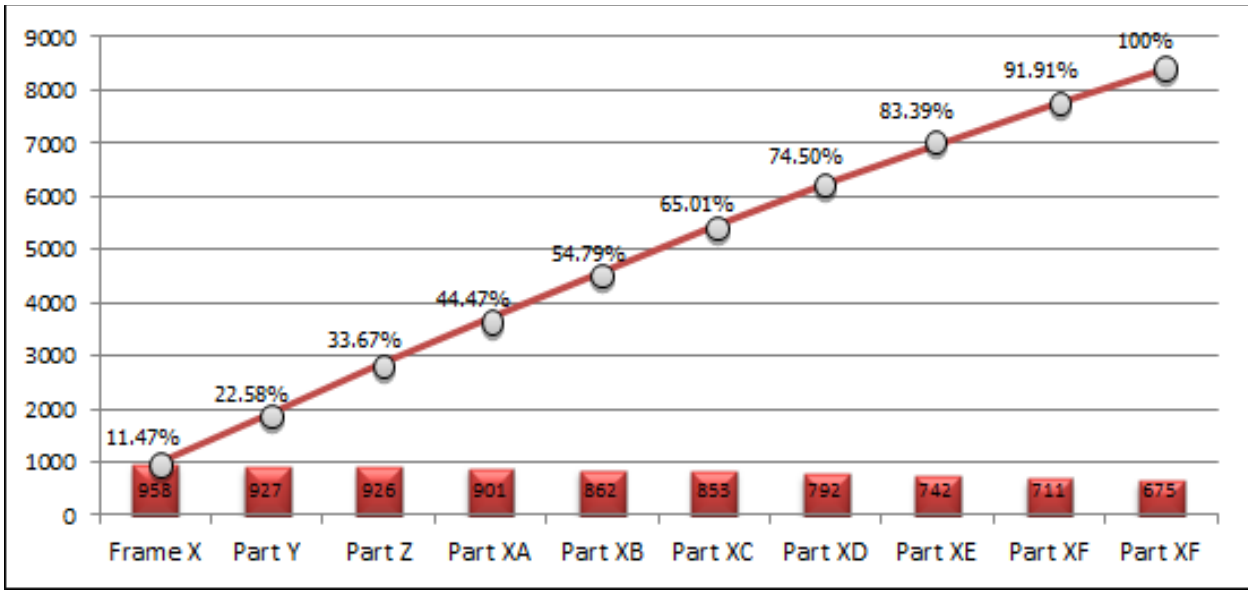

Gambar 2 Diagram Pareto Keluhan Pelanggan Bulan November 2017

Untuk mengetahui akar penyebab dari permasalahan ini, dilakukan analisis sebab akibat menggunakan diagram tulang ikan. Adapun diagram tulang ikan dapat dilihat pada Gambar 3. Berdasarkan gambar 3 dapat diketahui bahwa penyebab terjadinya masalah visual ini disebabkan oleh dua faktor, yaitu faktor metode dan faktor material. Pada faktor metode diketahui bahwa tidak ada standar pemeriksaan visual. Metode pemeriksaan yang ada hanya berdasarkan pengalaman masing-masing operator dikarenakan tidak ada standar pemeriksaan visual. Pada faktor material diketahui bahwa dimensi Collar tidak sesuai spesifikasi yang dipersyaratkan yaitu Std: $64 \pm$ 
02mm dan Act: $63.56 \mathrm{~mm}(\mathrm{NG})$. Setelah itu dilakukan rencana perbaikan yang ditunjukkan pada tabel 1.

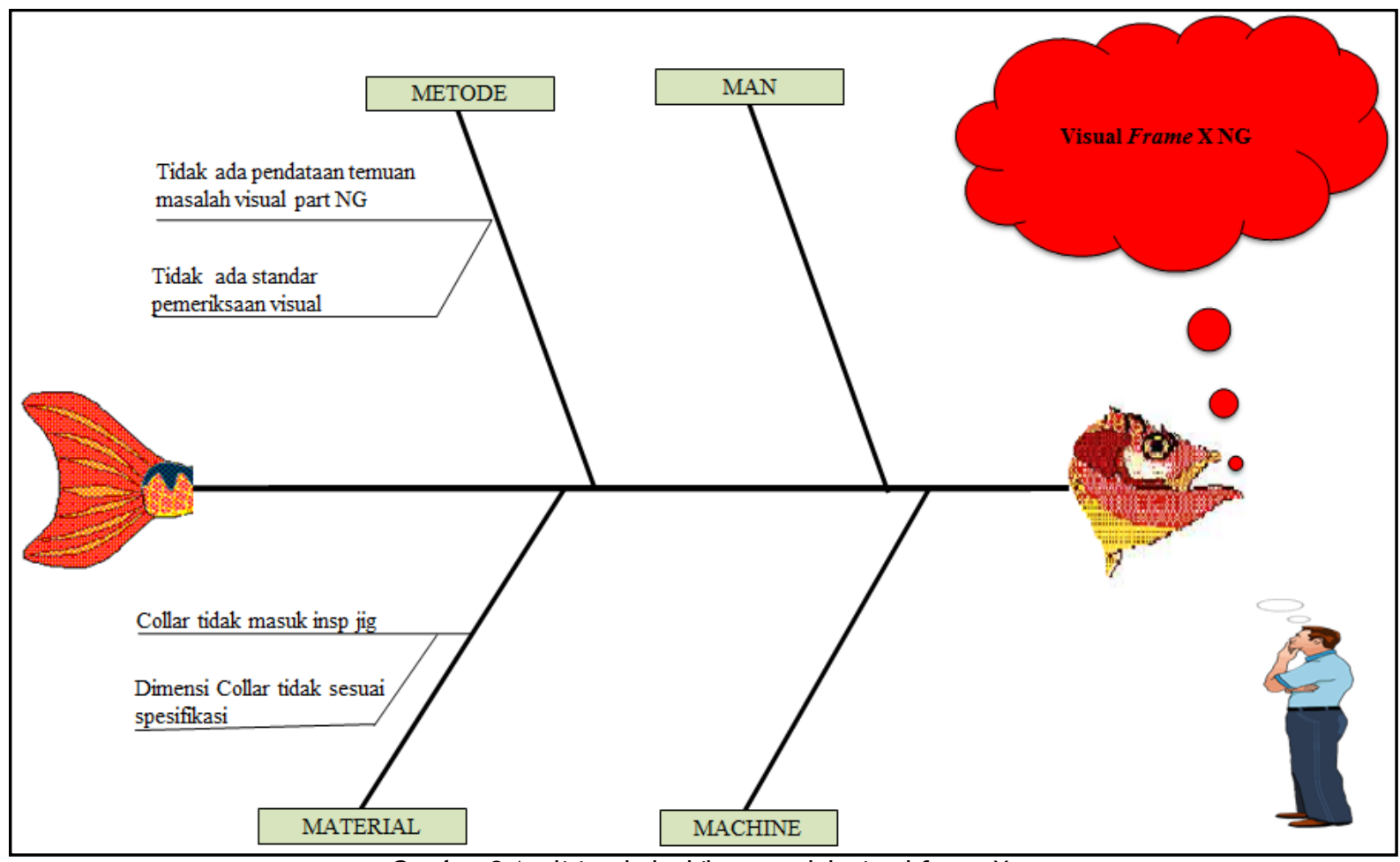

Gambar 3 Analisis sebab akibat masalah visual frame $X$

Tabel 1 Rencana perbaikan masalah visual frame $X$

\begin{tabular}{|c|c|c|c|c|c|}
\hline Apa & Kenapa & Dimana & Kapan & Siapa & Bagaimana \\
\hline $\begin{array}{l}\text { Operator } \\
\text { sulit } \\
\text { menentukan } \\
\text { part NG }\end{array}$ & $\begin{array}{l}\text { Tidak ada } \\
\text { panduan yang } \\
\text { baku terkait } \\
\text { pemeriksaan } \\
\text { visual part }\end{array}$ & Lini Produksi A & November 2017 & $\begin{array}{l}\text { Operator } \\
\text { cek visual } \\
\text { part }\end{array}$ & $\begin{array}{l}1 . \quad \text { Dibuatkan } \\
\text { Flow chart } \\
\text { penanganan } \\
\text { visual part NG } \\
\text { 2.Dibuatkan } \\
\text { instruksi kerja } \\
\text { pemeriksaan } \\
\text { visual part }\end{array}$ \\
\hline $\begin{array}{l}\text { Tidak ada } \\
\text { standar } \\
\text { pemeriksaan } \\
\text { visual }\end{array}$ & $\begin{array}{l}\text { Dokumen yang } \\
\text { ada PQCS } \\
\text { tidak } \\
\text { mengakomodir } \\
\text { secara detail } \\
\text { pemeriksaan } \\
\text { visual part. }\end{array}$ & Lini Produksi A & November 2017 & $\begin{array}{l}\text { 1. Operator } \\
\text { cek } \\
\text { Material } 2 . \\
\text { Operator } \\
\text { cek proses } \\
\text { 3. Operator } \\
\text { cek final } \\
\text { inspection }\end{array}$ & $\begin{array}{l}\text { 1. Dibuatkan } \\
\text { check sheet } \\
\text { untuk } \\
\text { pendataan } \\
\text { setiap temuan } \\
\text { masalah di seksi } \\
\text { penerimaan } \\
\text { material, proses } \\
\text { dan final } \\
\text { inspection } \\
\text { 2.Dibuatkan } \\
\text { Flow Chart } \\
\text { Penanganan } \\
\text { part Claim }\end{array}$ \\
\hline $\begin{array}{l}\text { Dimensi } \\
\text { Collar tidak } \\
\text { sesuai } \\
\text { spesifikasi }\end{array}$ & $\begin{array}{l}\text { Belum ada life } \\
\text { time tools } \\
\text { Collar }\end{array}$ & Lini Produksi A & November 2017 & Suplier & $\begin{array}{l}\text { Request } \\
\text { perbaikan, } \\
\text { collar harus } \\
\text { masuk standar }\end{array}$ \\
\hline
\end{tabular}


Berdasarkan tabel 1 diketahui langkah-langkah untuk menyelesaikan permasalahan, yaitu:

1. Dibuatkan Dibuatkan check sheet untuk pendataan setiap temuan masalah di seksi penerimaan material, proses dan final inspection.

2. Dibuatkan Flow Chart Penanganan part Claim.

3. Request ke supplier untuk perbaikan ukuran dan kesetabilan panjang collar.

Setelah menerapkan langkah-langkah perbaikan, didapatkan adanya penurunan jumlah part cacat pada bulan Desember 2017, yang ditunjukkan pada gambar 4.

* Problem NRC Bulan November 2017

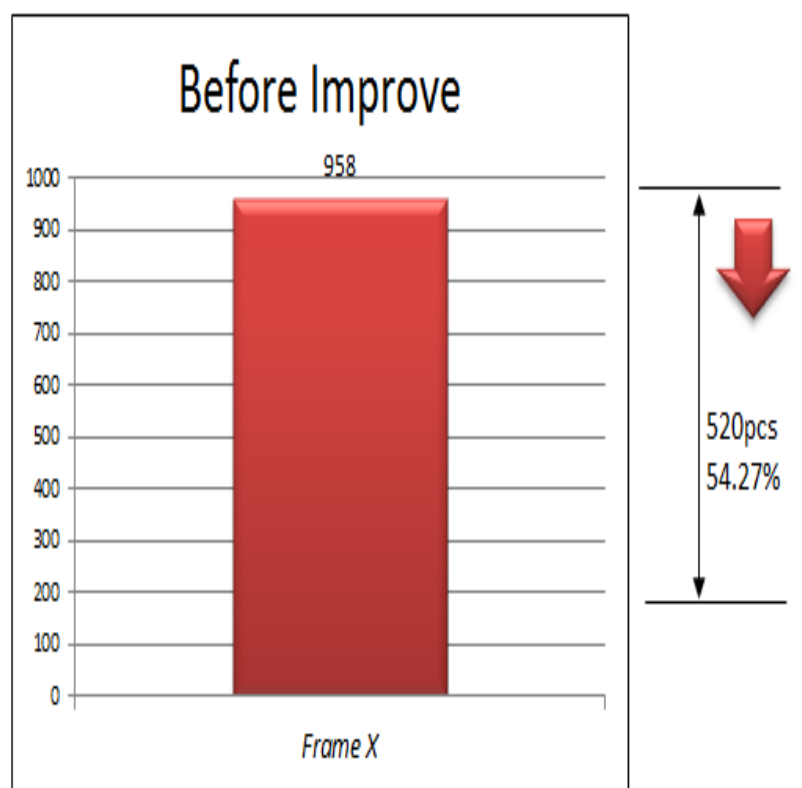

- Problem NRC Bulan Desember 2017

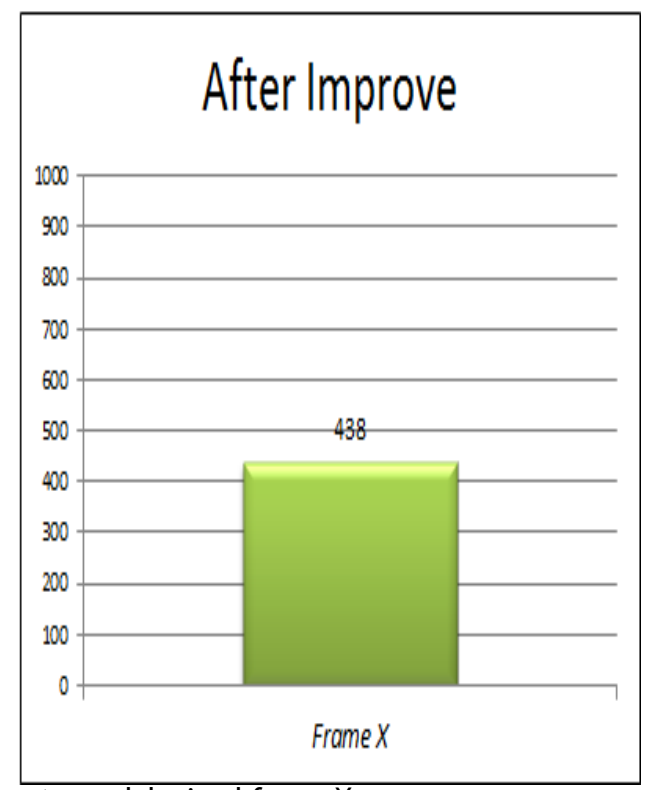

Gambar 4 Perbandingan jumlah cacat masalah visual frame $X$

Berdasarkan gambar 4 diketahui bahwa problem visual part mengelami penurunan sebanyak 520 pcs yaitu $54.27 \%$. Pencapaian ini jauh melebih target yang ditetapkan perusahaan, yaitu terjadai penurunan jumah cacat sebanyak $10 \%$.

\section{Simpulan}

Beberapa hal yang dapat disimpulkan pada penelitian ini adalah:

1. Penyebab tingginya keluhan pelanggan dan problem internal frame X di PT XYZ disebabkan oleh faktor metode dan material.

2. Masalah yang terjadi pada frame $X$ dapat dikurangi dengan perbaikan sebagai berikut: pembuatan check sheet, flow chart, dan menuntut perbaikan ke suplier collar agar terus membuat produk sesuai standar.

3. Terjadi penurunan jumlah cacat sebesar $54.27 \%$ setelah dilakukan perbaikan.

\section{Daftar Pustaka}

1. Assauri (1998). Manajemen produksi total - strategi peningkatan produktivitas bisnis global, Jakarta: gramedia pustaka utama.

2. Mulyadi (2002).Auditing, Edisi ke Enam, Cetakan Pertama, Jakarta: Salemba Empat.

3. Rangkuti, Freddy (2003). Measuring Customer Satisfaction, Jakarta: PT Gramedia Pustaka Utama. 